\title{
Caries Pattern in Primary Molars with Early Pulpal Involvement in Mixed Dentition
}

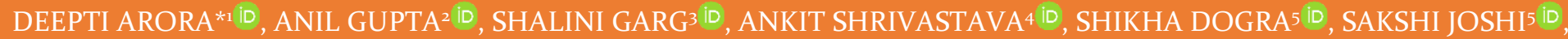
ADHISHREE SINGH CHIB

INTRODUCTION: Caries in primary dentition may lead to high risk in permanent dentition; it is therefore important to identify those children who are caries affected. Specific and distinct patterns of caries attack might indicate a distinct etiology or are most likely associated with the subsequent development of carious lesions on other surfaces of teeth.

AIM: To assess caries susceptibility and prevalence in primary teeth and evaluate the prevalence of caries according to individual molar surfaces in 4-8 year old children.

MATERIAL AND METHODS: A cross sectional retrospective study was conducted in the pediatric department of SGT Dental College using convenient sampling with caries in teeth as chief complaint. 70 radiographs were examined in the age group of 4-8 years. Lesions present on mesial distal and occlusal surfaces were recorded on the chart after radiographic examination.

RESULTS: As per results, distal surface of $\mathrm{D}(45.40 \%)$ and mesial surface of $\mathrm{E}(37.80 \%)$ showed maximum caries on adjacent proximal surfaces and significant dependence ( $\mathrm{p}$ value<0.05) was found between the presence of lesions on adjacent proximal surfaces. The $\mathrm{D}(76.1 \%)$ and $\mathrm{E}(79.1 \%)$ showed significantly higher caries experience on the proximal surfaces in conjunction with occlusal caries but were statistically not significant.

CONCLUSION: In the presence of non-proximal caries (occlusal caries), the chances of proximal caries are increased as seen radiographically. Thus need for treatment, are likely being underestimated during visual examinations alone.

KEYWORDS: Dental Caries, Mixed Dentition, Dental Pulp

\section{INTRODUCTION}

Dental caries is found to be the most vulnerable oral health issue and is a widespread oral disease in children across the world. The prevalence of cavitated carious lesions is of abundant concern over ages and is a predominant topic of several epidemiological studies conducted in India and abroad because it not only damages the tooth structure, but is also responsible for numerous disorders of mouth and other body systems $(\mathrm{WHO}, 1981) \cdot{ }^{1-3}$

Caries in primary dentition may lead to high risk in permanent dentition; it is therefore important to identify those children who are caries affected. It has been reported that caries distribution follows a typical pattern in the mixed dentition. The dental caries pattern varies with age, sex, race, feeding habits, oral hygiene practices, geographical location, and socioeconomic status. Moreover, the presence of two windows of infectivity by the time of mixed dentition makes caries occurrence unpreventable in addition to the above-mentioned etiological factors. Not every tooth and every surface are equally susceptible to caries. It is therefore important to know the relative caries susceptibility of the teeth in the maxillary and the mandibular arch. There is not much data about the association of pattern of early dental caries with the caries progression in mixed dentition period. Specific and distinct patterns of caries attack might indicate a distinct etiology or are most likely associated with the subsequent development of carious lesions on other surfaces of teeth. $\cdot^{4-7}$

Based on etiological factors caries pattern may vary. For instance, occlusal surfaces are the most susceptible, and labial and lingual surfaces the least susceptible in both the dentition. In addition, approximal surfaces are also commonly affected in mixed dentition after eruption of first permanent molars because the contact points of the primary molars become tighter. The broader proximal contact areas observed in primary teeth increase caries susceptibility as the self-cleansing action is reduced because of the limited movement thereby leading to increase in plaque accumulation. In neighbouring approximal tooth surfaces, caries susceptibility differs which shows that one surface may show obvious radiographic signs of caries, while the neighbouring surface does not. ${ }^{8-9}$

The aim of the present study was to assess caries susceptibility and prevalence in primary teeth and 
evaluate the prevalence of caries according to individual molar surfaces in 4-8 year old children.

The objectives were to evaluate the differences in caries prevalence and caries lesion location with regard to tooth surfaces in primary canines, first and second molars, to compare individual tooth surface caries rates and to evaluate correlation between caries on adjacent proximal surfaces and between proximal and occlusal caries.

\section{MATERIAL AND METHODS}

A cross sectional retrospective study was conducted in the pediatric department of SGT Dental College using convenient sampling with caries in teeth as chief complaint.

Parents and guardians of these children were asked to give informed written consent for participation in the study. Examined children were in the age group of 4-8 years. The study was performed with the consent of the ethical committee of the SGT University.

Materials: PMT Set, cotton rolls, CPI probe, radiographic films, dental charts

Methodology: The clinical examination was performed between mid-2018 -mid 2019 by trained dental examiners with standard dental mirror and probe under artificial light, using standardized criteria based on WHO guidelines. The status of occlusal, mesial and distal surfaces of primary canine, first and second molars and first permanent molar if visible were recorded separately from IOPA radiographs. The teeth considered in this study were C,D,E,6 and their surfaces mesial, distal and occlusal. Electronic patient records such as dental charts and radiographs were reviewed to obtain the data in this study.

Lesions present on mesial, distal and occlusal surfaces were recorded on the chart after radiographic examination. Charts and radiographs were screened by a single examiner using convenient sampling. 70 radiographs with carious lesions were studied and charts were prepared to calculate following outcomes:

-Correlation between caries on adjacent proximal surface lesions

- Frequency of proximal caries in teeth with and without occlusal caries
The statistical analysis was done using SPSS version 15.0 statistical analysis software. Chi-square test was used to assess the statistical significance and correlation between various surfaces. The level of statistical significance was taken as $\mathrm{p}<0.05$.

\section{RESULT}

A total of 70 radiographs of children aged 4-8 years with carious lesions were included in the study.

In Table 1, the correlation between adjacent proximal surface lesions showed that 21 adjacent proximal surfaces were seen i.e. mesial surface of 6 in contact with distal surface of $E$ and 5 (23.8\%) teeth with carious distal surface were found. 66 pairs with distal surface of $D$ and mesial surface of $E$ were examined [Figure $1(a)$ and (b)]. 25(37.8\%) out of 66 had caries on mesial surface of E and 30 (45.4\%) had caries on distal surface of D. It was also found that in distal of D and mesial of E group there were $14(21.2 \%)$ pairs with both surfaces carious, In another pair i.e. (mesial of D and distal of C) 18 teeth were examined in which one pair $(16.6 \%)$ in both surfaces had caries. It was also found that one (5.5\%) pair in this group had both surfaces carious (mesial of $\mathrm{D}$ and distal of $\mathrm{C}$ ). Figure 2 shows percentage of carious surfaces on the teeth examined in descending order -Distal surface of $\mathrm{D}(45.40 \%)>$ Mesial surface of $E(37.80 \%)>$ Distal surface of $E$ $(23.80 \%)>$ Mesial surface of D $(16.6 \%)>$ Distal surface of $\mathrm{C}(16.6 \%)>$ Mesial surface of $6(0 \%)$. A significant dependence ( $p$ value<0.05) was found between the presence of lesions on adjacent proximal surfaces.

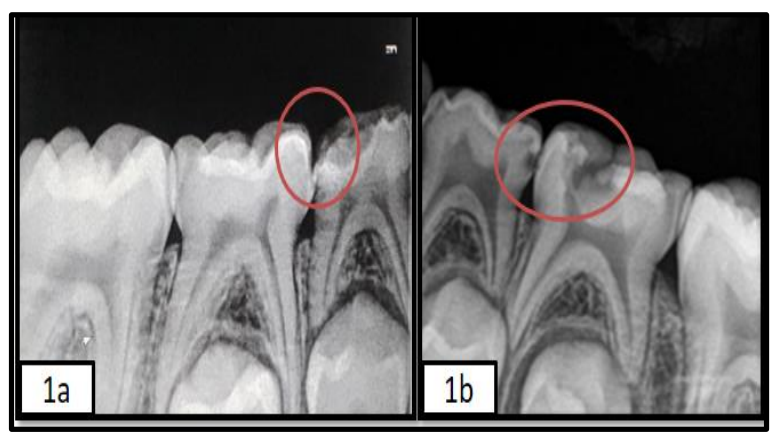

Figure 1 (a) and (b): Correlation between caries on adjacent proximal surfaces in descending order

In Table 2, Frequency of proximal caries in teeth with or without occlusal caries were examined. In E ,79.1\% (19 teeth with occlusal and proximal caries out of 24 


\begin{tabular}{|c|c|c|c|c|c|}
\hline $\begin{array}{l}\text { Arch and adjacent } \\
\text { paired surfaces }\end{array}$ & $\begin{array}{c}\text { Number of } \\
\text { pairs examined }\end{array}$ & $\begin{array}{l}\text { No. and \%age of } \\
\text { carious surfaces }\end{array}$ & $\begin{array}{l}\text { No. of pairs } \\
\text { with both } \\
\text { surfaces } \\
\text { carious }\end{array}$ & Chi square & p-value \\
\hline Mesial surface of 6 & \multirow[t]{2}{*}{21} & o \% & \multirow[t]{2}{*}{ o } & \multirow[t]{2}{*}{14.24} & \multirow[t]{2}{*}{$0.001(\mathrm{~S})$} \\
\hline Distal surface of $E$ & & $5(23.8 \%)$ & & & \\
\hline Mesial of E & \multirow[t]{2}{*}{66} & $25(37.8 \%)$ & \multirow[t]{2}{*}{$14(21.2 \%)$} & \multirow[t]{2}{*}{$17 \cdot 47$} & \multirow[t]{2}{*}{$0.001(S)$} \\
\hline Distal of D & & $30(45 \cdot 4 \%)$ & & & \\
\hline Mesial of D & \multirow[t]{2}{*}{18} & $1 / 6(16.6 \%)$ & \multirow[t]{2}{*}{$1(5 \cdot 5 \%)$} & \multirow[t]{2}{*}{9.65} & \multirow[t]{2}{*}{$0.001(\mathrm{~S})$} \\
\hline Distal of C & & $1 / 6(16.6 \%)$ & & & \\
\hline
\end{tabular}

Table 1. Correlation between caries on adjacent proximal surfaces

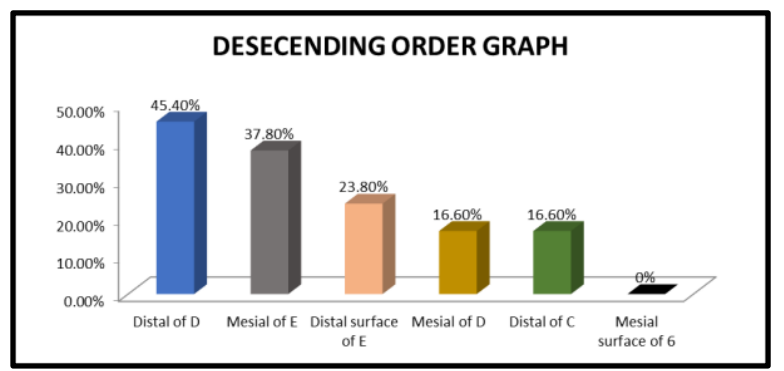

Figure 2: Correlation between caries on adjacent proximal surfaces in descending order

occlusal carious teeth) were found. In D, $76.1 \%$ (16 teeth with occlusal and proximal caries out of 21 occlusal carious teeth) were found.

In E, proximal caries were found in $40 \%$ (12 teeth without occlusal caries but with proximal caries out of 30 teeth without occlusal caries) of cases and in D, $51.6 \%$ (16 teeth without occlusal caries but with proximal caries out of 31 teeth without occlusal and proximal caries) were found.

Tooth number D and E showed significantly higher caries experience on the proximal surfaces in conjunction with occlusal caries but were statistically not significant.

\section{DISCUSSION}

In paediatric dentistry, knowledge of site of occurrence of carious lesions is crucial so that early interventions can be done as soon as the lesion is identified and the caries process is arrested, thereby, reducing potential stress and burden of disease for children and their families and in saving expenditure for health care services.

The basis of the site of caries occurrence, depends on various factors. Subka S et al., $2019^{10}$ have stated that the tight contact points between proximal surfaces of primary molars lead to higher plaque accumulation thus contributing to initiation and progression of proximal carious lesions. Moreover, the presence or absence of generalized spaces (Baume spaces) in primary dentition also leads to proximal lesions as there are primate spaces mesial to upper canine and distal to lower primary canine in mandibular arch because of which in mandibular primary first molar (D), distal surface has tight proximal contacts in comparison to the mesial surface thus leading to increased prevalence of caries (Addy M, 2006). ${ }^{11}$

The width of contact area affects the susceptibility to caries of the proximal surfaces. For instance, mesial surface of the first primary molar with narrow contact area adjacent to the distal surface of primary cuspid being much less susceptible than the distal surface. Another factor significantly influencing the risk of developing caries is morphology of approximal surfaces in primary molar teeth, in particular both surfaces being concave. ${ }^{12}$

The time of contact also influences the caries experience of the interproximal surfaces. For example, at the age of 6 , caries is found to be more prevalent between distal surface of $D$ and mesial surface of $E$ than distal surface of $E$ and mesial surface of first permanent molar. ${ }^{13}$

It was observed in the study that the first primary molar 


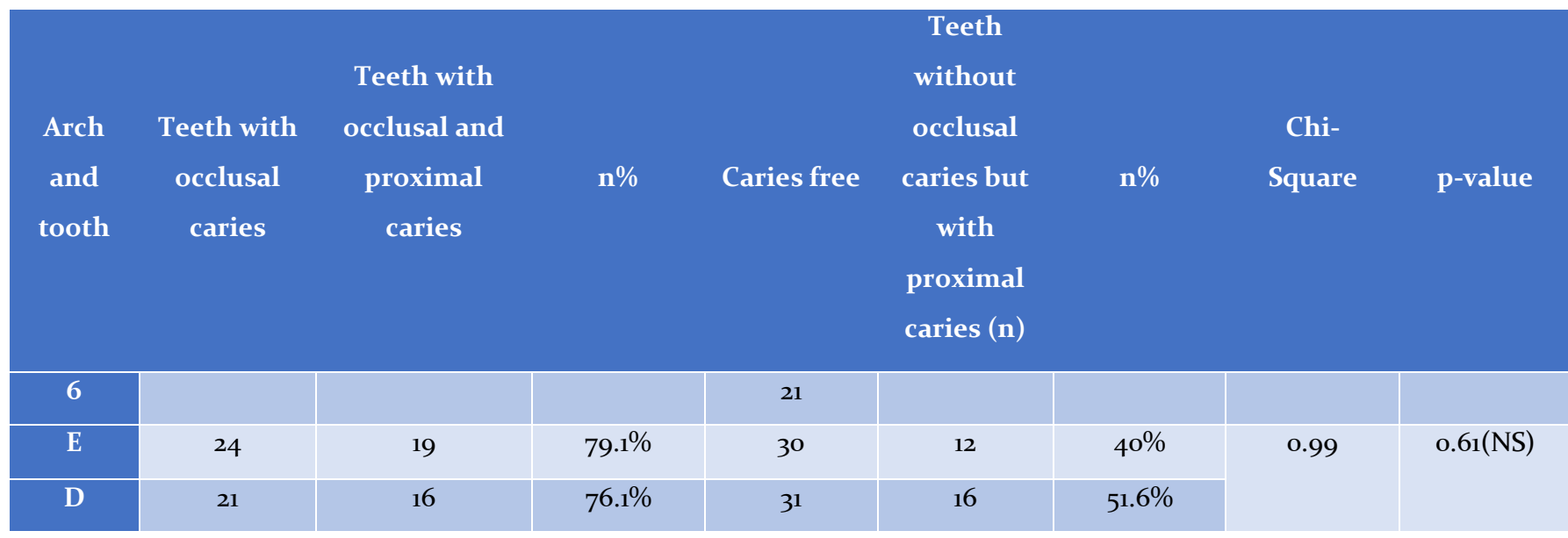

Table 2. Frequency of proximal caries in teeth with and without occlusal caries

had more caries prevalence when compared to the second molar. This is because of eruption sequence. The second primary molar erupts 10-12 months later than the first primary molar. Hereby, first primary molar remains for an overall longer duration in the oral cavity, thus it is more prevalent to caries (Torres BL et al. 2015). ${ }^{14}$

Table 1 showed that correlation between adjacent proximal surface lesions exists. It can be due to the fact that until eruption of the first permanent molars, the second primary molar has only one proximal surface (mesial) in contact with another tooth. On the other hand, first primary molar has contact points with both canine and second primary molar creating additional predilection site for developing proximal caries (Baume LJ., 1950)..$^{15}$ In a study, Bruzda-Zwiech A et al $(2015)^{16}$ stated that in 5-year-old children, distal surfaces were affected more in first molars than in second molars.

In another study, paired association of caries of primary second molar and permanent first molar though found in large number of cases was not significant in mixed dentition (Srinivasan D, Louis CJ, 2015). ${ }^{17}$ This is not in accordance with our study. Also, study by Subramaniam $P$ et al (2012) ${ }^{18}$ done in $4^{-6}$ year old children showed that tight proximal contacts in the primary dentition are at higher risk for dental caries.

In Table 2, it was observed that frequency of proximal caries in teeth with occlusal caries was more compared to those with only proximal caries. The frequency of proximal caries in teeth without occlusal caries should be taken into account when preventive treatment with pit and fissure sealant is considered. The value of sealant fissures of occlusal surface of primary molar at mixed dentition stage would be questionable because of high prevalence of proximal caries (Sreedevi A, Mohamed S, 2020). ${ }^{19}$ In a study by Dhar V et al. $(2018)^{20}$ found significant association between non-proximal carious lesions and radiographically detectable proximal carious lesions. Proximal lesions were twice as likely to exist on primary molars when non-proximal i.e., pit and fissure carious lesions were present which is in accordance with our study. As we know that, previous caries experience, parental education, socioeconomic status and mutans streptococci levels are among the reliable predictors for new caries and since caries experience is one of the best predictors for new caries, it initiates an interest to know if existing non proximal caries can serve as reliable objective criteria to predict the presence of proximal caries that may or may not be visible clinically.

\section{CONCLUSION}

- The width, morphology and time of contact significantly influences the pattern and frequency of caries on proximal surfaces in the mixed dentition period.

- In the presence of non-proximal caries i.e. occlusal caries the chances of proximal caries are increased as seen radiographically. Thus, need for treatment of caries, are underestimated during visual examinations alone.

\section{REFERENCES}

1. Sachdeva A, Punhani N, Bala M, Arora S, Gill GS, Dewan $\mathrm{N}$. The prevalence and pattern of cavitated carious lesions in primary dentition among children under 5 years age in Sirsa, Haryana (India). J Int Soc 
Prev Community Dent. 2015;5(6):494-8. https://doi.org/10.4103/2231-0762.170527

2. Rathee M, Sapra A. Dental Caries. In: StatPearls [Internet]. Treasure Island (FL): StatPearls Publishing; 2020. (Online Article). Available from: https://www.ncbi.nlm.nih.gov/books/NBK551699/ [Last Accessed on $15^{\text {th }}$ June, 2020]

3. Kassebaum NJ, Bernabé E, Dahiya M, Bhandari B, Murray CJ, Marcenes W. Global burden of untreated caries: a systematic review and meta regression. J Dent Res. 2015;94(5):650-8.

4. Heng C. Tooth Decay Is the Most Prevalent Disease. Fed Pract. 2016;33(10):31-3.

5. Ndagire B, Mwesigwa CL, Ntuulo JM, Mayanja-Kizza H, Nakanjako D, Rwenyonyi CM. Dental Caries Pattern and Treatment Needs among Ugandan Adolescent Students: A Cross-Sectional Study. Int J Dent. 2020;2020:8135865. https://doi.org/10.1155/2020/ 81358 65

6. Al-Samadani KH, Ahmad MS. Prevalence of first permanent molar caries in and its relationship to the dental knowledge of 9-12-year olds from Jeddah, kingdom of Saudi Arabia. ISRN Dent. 2012;2012:391068. https://doi.org/10.5402/2012/391068

7. Chandan GD, Saraf S, Sangavi N, Khatri A. Pattern of dental caries in 3-6-year-old children using decayed, missing, filled surface index and hierarchical caries pattern system: A descriptive study. J Indian Soc Pedod Prev Dent. 2018;36:108-12

8. Batchelor PA, Sheiham A. Grouping of tooth surfaces by susceptibility to caries: a study in 5-16 year-old children. BMC Oral Health. 2004;4(1):2. https://doi.org/10.1186/1472-6831-4-2

9. Demirci M, Tuncer S, Yuceokur AA. Prevalence of caries on individual tooth surfaces and its distribution by age and gender in university clinic patients. Eur J Dent. 2010;4(3):270-9.

10. Subka S, Rodd H, Nugent Z, Deery C. In vivo validity of proximal caries detection in primary teeth, with histological validation. Int J Paediatr Dent. 2019; 29:429-38.

11. Addy M. Tooth brushing, tooth wear and dentine hypersensitivity - are they associated? J Ir Dent Assoc. 2006;51(5):226-31.
12. Cortes A, Martignon S, Qvist V, Ekstrand KR. Approximal morphology as predictor of approximal caries in primary molar teeth. Clin Oral Investig. 2018;22(2):951-9. doi:10.1007/soo784-017-2174-3

13. Bimstein E, Eidelman E, Klein H, Chosack A. Distribution of caries in different tooth surfaces in 7year-old children. Caries Res. 1981;15(4):324-30. https://doi.org/10.1159/000260533

14. Torres BL, Martínez MMR, de Nova GJM. A study on the chronology and sequence of eruption of primary teeth in Spanish children. Eur J Paediatr Dent. 2015;16(4):301-4.

15. Baume LJ. Physiological tooth migration and its significance for the development of occlusion the biogenesis of the successional dentition. J Dent Res.1950 Jun; 29(3):338-48.

16. Bruzda-Zwiech A, Filipińska R, BorowskaStrugińska B, Żądzińska E, Wochna-Sobańska M. Caries Experience and Distribution by Tooth Surfaces in Primary Molars in the Pre-school Child Population of Lodz, Poland. Oral Health Prev Dent. 2015;13(6):55766. https://doi.org/10.3290/j.ohpd.a34371

17. Srinivasan D, Louis CJ. Evaluation of caries in deciduous second molar and adjacent permanent molar in mixed dentition. J Pharm Bioallied Sci. 2015;7(Suppl 2):S572-S575. https://doi.org/10.4103/o9 75-7406.163544

18. Subramaniam P, Babu Kl G, Nagarathna J. Interdental spacing and dental caries in the primary dentition of 4-6 year old children. J Dent (Tehran). 2012;9(3):207-14.

19. Sreedevi A, Mohamed S. Sealants, Pit and Fissure. In: StatPearls [Internet]. Treasure Island (FL): StatPearls Publishing; (Online Article). Available from: https://www.ncbi.nlm.nih.gov/books/NBK448116/ [Last Accessed on $15^{\text {th }}$ June, 2020]

20. Dhar V, Mon S, Macek MD. Evaluation of Nonproximal Caries as Predictor of Proximal Caries in Primary Molars. Int J Clin Pediatr Dent. 2018 NovDec;11(6):457-461. https://doi.org/10.5005/jp-journals10005-1557. 
Cite this article as:

Arora D, Gupta A, Garg S, Shrivastava A, Dogra S, Joshi S, Chib AS. Caries Pattern in Primary Molars with Early Pulpal Involvement in Mixed Dentition. Int Healthc Res J. 2021;4(10):OR1OR6. https://doi.org/10.26440/IHRJ/0410.01378

AUTHOR AFFILIATIONS: $\left({ }^{*}\right.$ Corresponding Author)

1. Post Graduate Student [(ORCID ID: https://orcid.org/oooo-0oo3-08oo-8421, Dr. Deepti Arora), (ORCID ID:

https://orcid.org/oooo-0002-5117-8322, Dr. Adhishree Singh Chib)]

2. Professor \& Head of the Department (ORCID ID: https://orcid.org/oooo-0002-848-942X)

3. Professor (ORCID ID: https://orcid.org/oooo-0oo1-5931-0693)

4. Reader (ORCID ID: https://orcid.org/oooo-0003-4429-6387)

5. Senior Lecturer [(ORCID ID: https://orcid.org/oooo-0oo2-4166-3965, Dr. Shikha Dogra),

(ORCID ID: https://orcid.org/oooo-0003-1000-3486, Dr. Sakshi Joshi)]

Department of Pediatric \& Preventive Dentistry, Faculty of Dental Sciences, SGT University, Gurugram

Source of support: Nil, Conflict of interest: None declared
Contact Corresponding Author at: mongadeepti[at]gmail[dot]com 